\title{
The self-administration of dapsone by leprosy patients in Ethiopia
}

\author{
GA ELLARD*, JMH PEARSON ${ }^{\dagger} \&$ GS HAILE ${ }^{\dagger}$ \\ *MRC Unit for Laboratory Studies of Tuberculosis, Royal \\ Postgraduate Medical School, Ducane Road, London W12 OHS, \\ England and $t_{\text {Medical Research Council Leprosy Project, All }}$ \\ Africa Leprosy and Rehabilitation Training Centre, Addis Ababa, \\ Ethiopia
}

Received for publication 5 February 1981

\begin{abstract}
Summary In a second investigation of the regularity of dapsone selfadministration among outpatients in Addis Ababa, the compliance of patients participating in a trial to assess the ability of combinations of dapsone, thiacetazone and rifampicin to prevent relapse with dapsoneresistant leprosy was compared with that of non-trial patients. Despite the considerable additional time spent on encouraging the trial patients to take their treatment regularly, their level of dapsone compliance was similar to that of the non-trial patients. Only about $60 \%$ of the 295 outpatients studied appeared to be ingesting their prescribed dapsone treatment regularly and the overall level of dapsone compliance resembled that encountered in the first investigation conducted 6 years previously. The taking of thiacetazone by the trial patients whose dapsone treatment was supplemented with this drug was unsatisfactory. The implications of these findings for the outpatient treatment of lepromatous leprosy are discussed.
\end{abstract}

\section{Introduction}

The treatment of leprosy continues to be based on the long-term daily selfadministration of oral doses of dapsone. The regularity with which patients actually ingest their prescribed treatment can be assessed by means of a quantitative urine-test method. ${ }^{1}$ In this method the ratio of the concentration

\section{Present addresses:}

G A Ellard, National Institute for Medical Research, London NW7 1 AA, England.

J M H Pearson, Dhoolpet Leprosy Research Centre, Hyderabad 500006, Andra Pradesh, India.

G S Haile, Addis Ababa Leprosy Hospital, PO Box 165, Addis Ababa, Ethiopia. 
of dapsone plus its diazotizable metabolites to creatinine in the urine is determined using simple colorimetric methods (' $\mathrm{D} / \mathrm{C}$ ratio') and the $\mathrm{D} / \mathrm{C}$ ratios of urine samples collected from outpatients self-administering their dapsone treatment compared with those from inpatient controls given the same daily dose of dapsone under strict supervision. When this method was first used to monitor dapsone self-administration in Ethiopia $^{2}$ and $\mathrm{Malawi}^{3}$ it was concluded that only about $50-60 \%$ of the outpatients studied were ingesting their prescribed treatment regularly. Subsequent investigations ${ }^{4-8}$ have indicated that poor dapsone compliance is probably a world-wide problem.

During the 6 years since we first assessed the extent of dapsone selfadministration by outpatients receiving treatment from the Addis Ababa Leprosy Hospital there has been an alarming spread of dapsone-resistant strains of Mycobacterium leprae in the area. ${ }^{9}$ This development has highlighted the importance of prescribing lepromatous patients the maximum well-tolerated dosage of dapsone, of supplementing dapsone treatment with other potent antileprosy drugs and of encouraging regular self-medication. This paper describes the results of a second investigation of compliance among outpatients in Addis Ababa with the object of assessing whether significant changes have taken place since the previous investigation in the regularity of dapsone self-administration and if drug taking could be improved by educational means.

\section{Methods}

\section{Patients and samples}

Urine samples were collected from lepromatous patients who were participating in a trial to assess the ability of combinations of dapsone, thiacetazone and rifampicin to prevent patients relapsing with dapsone-resistant leprosy. Over 800 patients weighing $40 \mathrm{~kg}$ and over were randomly allocated to 4 treatment groups. Group A received 1 tablet of $100 \mathrm{mg}$ dapsone daily for 12 months. Group B received $100 \mathrm{mg}$ dapsone plus $150 \mathrm{mg}$ thiacetazone daily for 12 months while in group $C$ this treatment was supplemented with $600 \mathrm{mg}$ rifampicin daily given during months 1 and 7. Group D received 12 months daily dapsone plus daily rifampicin during months 1 and 7. Thiacetazone was given in the form of 'Thiazina' tablets $(150 \mathrm{mg}$ thiacetazone plus $300 \mathrm{mg}$ isoniazid) since these were readily available and widely used for the treatment of tuberculosis in Ethiopia, and no more expensive than thiacetazone tablets which were hard to obtain.

Patients collected a 4-week stock of medicaments at each visit to the outpatient clinic. In order to encourage patients to take their treatment regularly, the MRC Project staff gave considerable time to health education, discussing each patient's treatment with him at the time of his entry into the trial. There 
was little need to explain how frequent dapsone-resistant leprosy had become; the fact that many patients' disease got worse after years of treatment was common knowledge. Emphasis was therefore laid on the value of the additional treatment which, if taken regularly together with their dapsone tablets, should prevent such an occurrence. Patients were also warned that the additional thiacetazone or rifampicin treatment might sometimes have unpleasant sideeffects but they were urged not to prematurely stop treatment in the event of an adverse reaction but to discuss any symptoms with the clinic staff before contemplating changing treatment. At the end of the 12 months all the patients then continued treatment with $100 \mathrm{mg}$ dapsone daily.

Urine samples were collected on the occasion of a clinic visit from 73 patients in the twelfth month of the trial and from another 63 trial patients who had completed their trial treatment 6 months previously. In order to compare the compliance of patients in the study with an appropriate control group, urine samples were also collected from 222 non-trial patients attending the outpatient clinic whose prescribed daily dose of dapsone was also $100 \mathrm{mg}$. Whenever urine samples were collected, patients were asked whether they still had any remaining tablets of dapsone at home. Urine samples were preserved by the addition of a crystal of thymol and stored refrigerated to prevent undue evaporation prior to their analysis in London.

\section{Analytical methods}

Urinary concentrations of dapsone plus its diazotizable metabolites (as dapsone equivalents) and creatinine were determined by modifications of the Bratton and Marshall ${ }^{10}$ and alkaline picrate procedures. ${ }^{1}$ Urine samples from the trial patients prescribed Thiazina (Groups B and C) were also tested for the presence of the isoniazid metabolites isonicotinic acid and isonicotinylglycine by the qualitative procedure described by Ellard and Greenfield. ${ }^{11}$

\section{Results and Discussion}

The dapsone/creatinine ratios of the urine samples collected from the patients are summarized in Table 1. These ratios have been interpreted by comparison with those obtained in the previous Ethiopian dapsone compliance investigation from untreated controls and from samples collected $24 \mathrm{~h}$ after the last of a series of daily doses of $100 \mathrm{mg}$ dapsone given to inpatients under strict supervision. ${ }^{2}$ On the basis of these control results outpatients were considered to be taking dapsone 'regularly' if their D/C ratios exceeded $30 \mu \mathrm{g} / \mathrm{mg}$. The great majority of these patients had probably ingested a $100 \mathrm{mg}$ tablet of dapsone within the $24 \mathrm{~h}$ prior to their visit to the clinic and a substantial proportion of these patients had probably taken their last dose on the morning of their clinic 
Table 1. Dapsone/creatinine ratios of urine samples

\begin{tabular}{|c|c|c|c|}
\hline \multirow[b]{2}{*}{ Origin of samples* } & \multirow{2}{*}{$\begin{array}{l}\text { No. of } \\
\text { subjects }\end{array}$} & \multicolumn{2}{|c|}{$\mathrm{D} / \mathrm{C}$ ratios $(\mu \mathrm{g} / \mathrm{mg})^{\dagger}$} \\
\hline & & Range & Mean $\ddagger$ \\
\hline Controls not on dapsone $\S$ & 27 & $4.0-10.9$ & $7.0 \pm 0.3$ \\
\hline Supervised controls on dapsone ${ }^{\S}$ & 27 & $36.9-123$ & $79.7 \pm 4.6$ \\
\hline Non-trial patients & 222 & & \\
\hline Taking dapsone regularly* & $139(63 \%)$ & $30.1-312$ & $98.1 \pm 4.5$ \\
\hline Taking dapsone irregularly* & $58(26 \%)$ & $10.1-30.0$ & $17.5 \pm 0.8$ \\
\hline Taking dapsone grossly irregularly* & $25(11 \%)$ & $5.2-9.9$ & $7.9 \pm 0.3$ \\
\hline Patients during trial & 73 & & \\
\hline Taking dapsone regularly & $43(59 \%)$ & $32.4-275$ & $109.1 \pm 9.9$ \\
\hline Taking dapsone irregularly & $25(34 \%)$ & $10.2-28.7$ & $18.3 \pm 1.2$ \\
\hline Taking dapsone grossly irregularly & $5(7 \%)$ & $4.5-9.2$ & $7.2 \pm 0.9$ \\
\hline Patients after trial & 63 & & \\
\hline Taking dapsone regularly & $24(38 \%)$ & $32.2-199$ & $116.2 \pm 9.5$ \\
\hline Taking dapsone irregularly & $28(44 \%)$ & $10.1-29.6$ & $17.6 \pm 1.3$ \\
\hline Taking dapsone grossly irregularly & $11(17 \%)$ & $3.9-9.6$ & $7.7 \pm 0.6$ \\
\hline
\end{tabular}

*For details and definitions see text.

$\dagger \mu \mathrm{g}$ dapsone equivalents per mg creatinine.

¥ Mean \pm standard deviation of mean.

$\S$ Results from previous investigation (Low and Pearson, 1974).

visit since the $\mathrm{D} / \mathrm{C}$ ratios of about a third of these samples exceeded the maximum value $(123 \mu \mathrm{g} / \mathrm{mg})$ encountered among the controls.

Patients whose urine samples had D/C ratios of $10-30 \mu \mathrm{g} / \mathrm{mg}$ were considered to be taking their dapsone 'irregularly'. If the $\mathrm{D} / \mathrm{C}$ ratios of these patients were typical of their long-term pattern of dapsone self-administration, then a comparison of their mean $\mathrm{D} / \mathrm{C}$ ratios (about $18 \mu \mathrm{g} / \mathrm{mg}$ ) with those of the controls $^{2}, 3$ would suggest that on average these patients were only taking about $15 \%$ of their prescribed treatment. Alternatively, by considering the kinetic profile of $\mathrm{D} / \mathrm{C}$ ratios after oral dosage with dapsone it may be calculated that on average such patients probably took their last dapsone dose some 3-4 days prior to their visit to the clinic. ${ }^{8,12}$ Patients with urine $\mathrm{D} / \mathrm{C}$ ratios of less than $10 \mu \mathrm{g} / \mathrm{mg}$ were considered to be 'grossly irregular' in ingesting their treatment. Since their mean $\mathrm{D} / \mathrm{C}$ ratios did not differ significantly from those of the untreated controls, it is probable that the great majority of these patients had taken no dapsone for at least 5 days before coming to the clinic.

About $60 \%$ of the non-trial patients were judged to be self-administering their dapsone regularly, a proportion similar to that found in the original investigation carried out 6 years previously. ${ }^{2}$ Although the overall level of compliance has therefore probably not changed significantly during this time, the great majority of patients are now being prescribed $100 \mathrm{mg}$ dapsone daily 
whereas previously the prescription of 50 or $25 \mathrm{mg}$ daily doses was quite common, so that the overall level of dapsone intake has probably been considerably improved.

Disappointingly, the considerable efforts devoted to encouraging the trial patients to take their treatment regularly appear to have been unsuccessful, at least as judged by the results obtained on the urine samples collected at the end of the trial. Thus the proportions of trial patients considered to be 'irregular' or 'grossly irregular' in self-administering their dapsone tablets were similar to those encountered among the non-trial patients. Indeed, the compliance of the trial patients 6 months after the end of the trial appeared to be inferior to that of the non-trial patients. Separate analyses (not shown) indicated that the D/C ratios of samples collected from patients who stated that they still had some remaining dapsone tablets at home did not differ significantly from those who said their stock of pills was finished.

Forty-five urine samples collected during the twelfth month of the trial from patients who had been prescribed thiacetazone in the form of daily Thiazina tablets were tested by the isonicotinic acid procedure. ${ }^{11}$ Positive results were obtained from 13 of the samples indicating that only about $30 \%$ of the patients had ingested a Thiazina tablet within the previous 48 h. ${ }^{11,13}$ It was therefore apparent that the prescribed thiacetazone supplement was being taken very irregularly by many of the patients in the trial, perhaps on account of adverse side-effects experienced by about a quarter of the patients who had been prescribed the drug.

\section{Discussion}

The results of this study have confirmed the now well-documented conclusion that although dapsone is a well-tolerated drug, many patients self-administer it irregularly. ${ }^{2-8}$ The failure of our efforts to encourage patients to take their treatment regularly indicates that improving patient compliance is likely to be a difficult task. It may be that many patients have previously been unwittingly encouraged to associate the taking of dapsone with the occurrence of reactions because of the widespread practice of stopping dapsone treatment during bouts of both ENL or upgrading reactions, or it could be that the problem of non-compliance in leprosy had deeper psychological foundations. The many years that lepromatous patients need to continue with their treatment is almost certainly another factor militating against regular drug self-administration, since experience in the treatment of other chronic conditions such as hypertension, schizophrenia and tuberculosis has shown that patient compliance deteriorates with increasing duration of therapy. ${ }^{14}$ Furthermore, all previous attempts to improve compliance by educating diabetic, hypertensive or tuberculosis patients about the importance of regularly self-administering their treatment have failed. ${ }^{15}$ 
Although it is probable that a few missed daily doses of dapsone are unlikely to significantly impair the efficacy of therapy, substantial breaks in drug taking which result in dapsone concentrations in the body falling to levels that permit dapsone-resistant mutants of $M$. leprae to multiply cannot but increase the risk of patients eventually relapsing with dapsone-resistant leprosy. It is therefore likely that a substantial proportion of the patients considered to be self-administering their dapsone grossly irregularly (10\% of the total) will eventually incur therapeutic penalties as a result of their poor compliance and that some of those judged to be taking dapsone irregularly (30\% of the total) could also be at risk.

The irregularity with which the patients ingested their prescribed thiacetazone was also very disquieting. Mouse foot-pad studies have shown that the activity of thiacetazone against $M$. leprae is essentially bacteriostatic ${ }^{16}$ and that its efficacy is substantially impaired if it is given intermittently. ${ }^{17}$ Since peak serum concentrations of thiacetazone achieved in man after daily dosage with $150 \mathrm{mg}$ thiacetazone only exceed its minimal inhibitory concentration against $M$. leprae by a factor of about eight-fold ${ }^{18}$ and its half-life is about $21 \mathrm{~h},{ }^{19}$ it may be anticipated that gaps of as little as 3 or 4 days may seriously impair its efficacy as a companion drug to prevent lepromatous patients relapsing with dapsone-resistant leprosy.

The implications of our findings are two-fold. Firstly, consideration should be given to supplementing self-administered daily dapsone treatment with supervised doses of rifampicin, the most potent bactericidal antileprosy drug. Thus a $600 \mathrm{mg}$ dose of rifampicin might be given once monthly at the time of each clinic visit ${ }^{20}$ and, if finances permit, the regimen might be strengthened by giving a second $600 \mathrm{mg}$ dose of rifampicin to be swallowed the following day. ${ }^{21}$ Secondly, before any decisions are made to employ companion drugs such as thiacetazone, ethionamide or prothionamide that need to be taken on a daily basis $^{17,18}$ for routine treatment, studies should first be carried out to determine the regularity with which they are likely to be self-administered by outpatients. Such compliance studies should be considerably facilitated by the recent discovery of the potentialities of using a minute dose of isoniazid as an innocuous marker for monitoring drug ingestion. ${ }^{13}$

\section{References}

1 Ellard GA, Gammon PT, Helmy HS, Rees RJW. Urine tests to monitor the selfadministration of dapsone by leprosy patients. Am J Trop Med Hyg, 1974, 23, 464-70.

2 Low SJM, Pearson JMH. Do leprosy patients take DDS regularly? Lepr Rev, 1974, 45, 218-23.

${ }^{3}$ Ellard GA, Gammon PT, Harris JM. The application of urine tests to monitor the regularity of dapsone self-administration. Lepr Rev, 1974, 45, 224-34. 
${ }^{4}$ Huikeshoven HCJ, Honhoff C, Van Eys GJJM, Anten JGF, Mayer JMA, Van Helden HPT. Weekly self-medication of leprosy patients monitored by DDS/creatinine ratios in urines. Lepr Rev, 1976, 47, 201-9.

5 Naik SS, Ganapati R. Regularity of dapsone intake by leprosy patients attending urban treatment centre. Lepr India, 1977, 49, 207-15.

6 Balakrishnan S. Monitoring self-administration of dapsone by patients. Lepr India, 1977, 49, 364-71.

7 Hagan KJ, Smith SE, Gyi KM, Lwin MM, Myaing YY, Oo KM, Shwe T, Tin KM, Than KN, Hla T, Kywe WW. The reliability of self-administration of dapsone by leprosy patients in Burma. Lepr Rev, 1979, 50, 201-11.

${ }^{8}$ Cates CJ. An assessment of dapsone self-administration in Gudiyatham Taluk. How should urinary dapsone/creatinine ratios be used? Lepr Rev, 1981 52, 55-64.

9 Pearson JMH, Haile GS, Barnetson RSC, Rees RJW. Dapsone-resistant leprosy in Ethiopia. Lepr Rev, 1979, 50, 183-99.

10 Bratton AC, Marshall EK. A new coupling component for sulfanilamide determination. $J$ Biol Chem, 1939, 128, 537-50.

11 Ellard GA, Greenfield C. A sensitive urine-test for monitoring the ingestion of isoniazid. $J$ clin Path, 1977, 30, 84-7.

12 Ellard GA. Profile of urinary dapsone/creatinine ratios after oral dosage with dapsone. Lepr Rev, 1980, 51, 229-36.

13 Ellard GA, Downs PA, Jenner PJ. An evaluation of the potential use of isoniazid, acetylisoniazid and isonicotinic acid for monitoring the self-administration of drugs. $\mathrm{Br} J$ clin Pharmac, 1980, 10, 369-81.

14 Haynes RB. Determinants of compliance: The disease and the mechanics of treatment. In: Haynes RB, Taylor DW, Sackett DL, eds. Compliance in Health Care. John Hopkins University Press, 1979, 49-62.

15 Haynes RB. Strategies to improve compliance with referrals, appointments, and prescribed medical regimens. In: Haynes RB, Taylor DW, Sackett DL, eds. Compliance in Health Care. Johns Hopkins University Press, 1979, 121-43.

16 Colston MJ, Hilson GRF, Banerjee DK. The 'proportion bactericidal test': A method for assessing bactericidal activity of drugs against Mycobacterium leprae in mice. Lepr $R e v, 1978,49,7-15$.

17 Colston MJ, Hilson GRF, Lancaster RD. Intermittent chemotherapy of experimental leprosy in mice. Amer J Trop Med Hyg, 1980, 29, 103-8.

18 Colston MJ, Ellard GA, Gammon PT. Drugs for combined therapy: Experimental studies on the antileprosy activity of ethionamide and prothionamide, and a general view. Lepr Rev, 1978, 49, 115-26.

19 Jenner PJ, Ellard GA (in preparation).

20 Ellard GA. Combined treatment for lepromatous leprosy. Lepr Rev, 1980, 51, 199-205.

21 Rees RJW. Rifampicin: the investigation of a bactericidal drug. Lepr Rev, 1975, 46 (Supp1.), 121-4. 